\section{Perjalanan Lahirnya Khazanah: Jurnal Pengembangan Kearsipan}

\author{
Musliichah, S.I.P., M.A.
}

Arsip UGM sebagai lembaga kearsipan perguruan tinggi pertama di Indonesia memiliki visi menjadi pusat pengembangan dan layanan informasi kearsipan dalam menunjang universitas riset kelas dunia dan bertata kelola baik. Salah satu misi Arsip UGM adalah melaksanakan dan mengoptimalkan layanan internal dan eksternal informasi kearsipan. Dalam rangka memberikan layanan yang optimal di bidang kearsipan kepada lingkungan internal UGM dan masyarakat eksternal, Arsip UGM mengembangkan program publikasi kearsipan. Tujuan dari program publikasi kearsipan adalah menyosialisasikan kearsipan dan melakukan edukasi kearsipan kepada publik baik internal maupun eksternal UGM.

Khazanah: Jurnal Pengembangan Kearsipan merupakan salah satu media publikasi kearsipan yang dikembangkan oleh Arsip UGM. Media publikasi ini merupakan pengembangan dari News Letter yang diterbitkan Arsip UGM sejak April 2005 yang terbit tiap bulan hanya berupa 1 lembar kertas 4 halaman. News Letter dalam format ini terakhir diterbitkan pada Desember 2006. Januari 2007 News Letter diubah tampilannya menjadi buku mini dicetak berwarna dengan jumlah halaman lebih dari 4 halaman. News Letter dengan format ini terbit hingga Mei 2008.

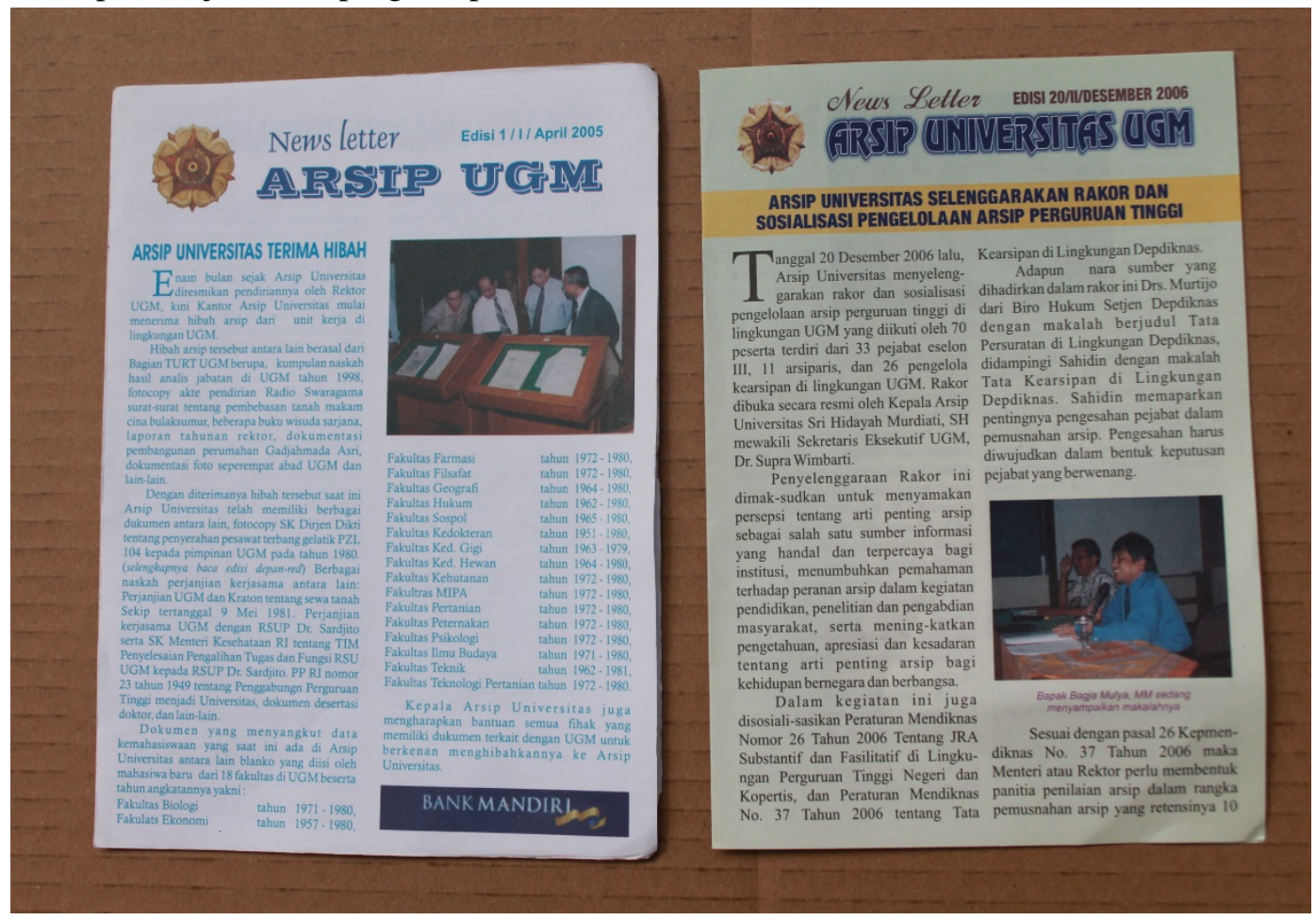

Gambar 1. News Letter 2 lembar edisi pertama April 2005 dan Edisi terakhir Desember 2006. 


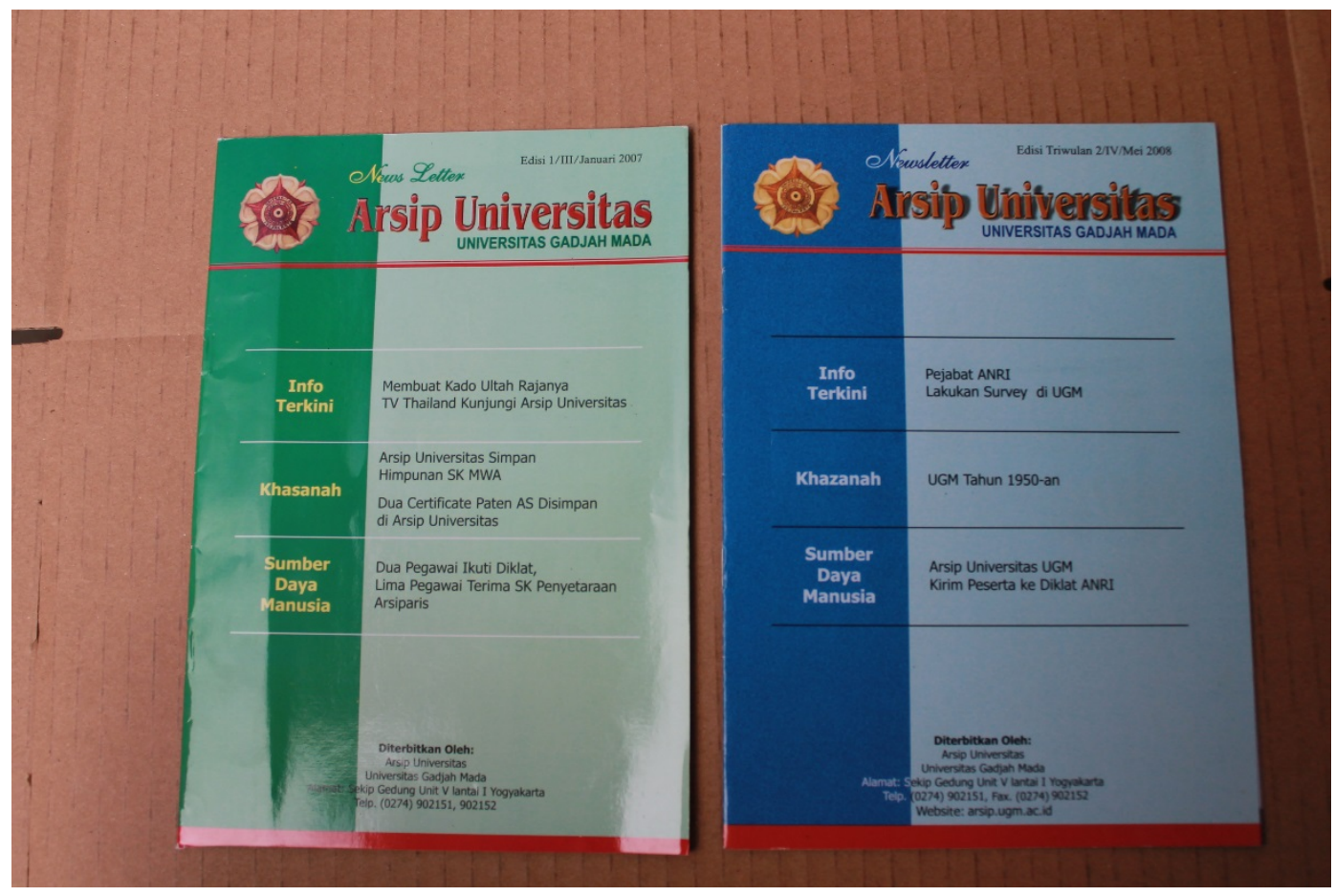

Gambar 2. News Letter bentuk buku (edisi pertama Januari 2007 dan terakhir Mei 2008

Tahun 2007 Arsip UGM mengajukan ijin ke PDII LIPI untuk mengembangkan News Letter menjadi Jurnal. PDII LIPI menyetujui permohonan pengembangan News Letter menjadi jurnal dengan nama "Khazanah: Jurnal Pengembangan Kearsipan" dengan nomor ISSN 1978-4880. Ijin PDII LIPI tersebut kemudian ditindaklanjuti dengan menerbitkan media publikasi pengganti News Letter.
Volume pertama terbit pada September 2008. Pertama kali terbit tahun 2008, media ini belum sepenuhnya berformat jurnal sehingga nama yang digunakan adalah Khazanah: Buletin Kearsipan. Khazanah terbit 3 kali dalam setahun yaitu Maret, Juli dan November. Tahun 2013 terjadi perubahan pada penerbitan Khazanah.

Format Khazanah sudah mengarah pada jurnal dengan layout dan bobot isi artikel ditingkatkan. Nama Khazanah pada terbitan volume 6 Nomor 1 Maret 2013 berubah menjadi Khazanah (tidak diikuti sub judul Buletin Kearsipan). 


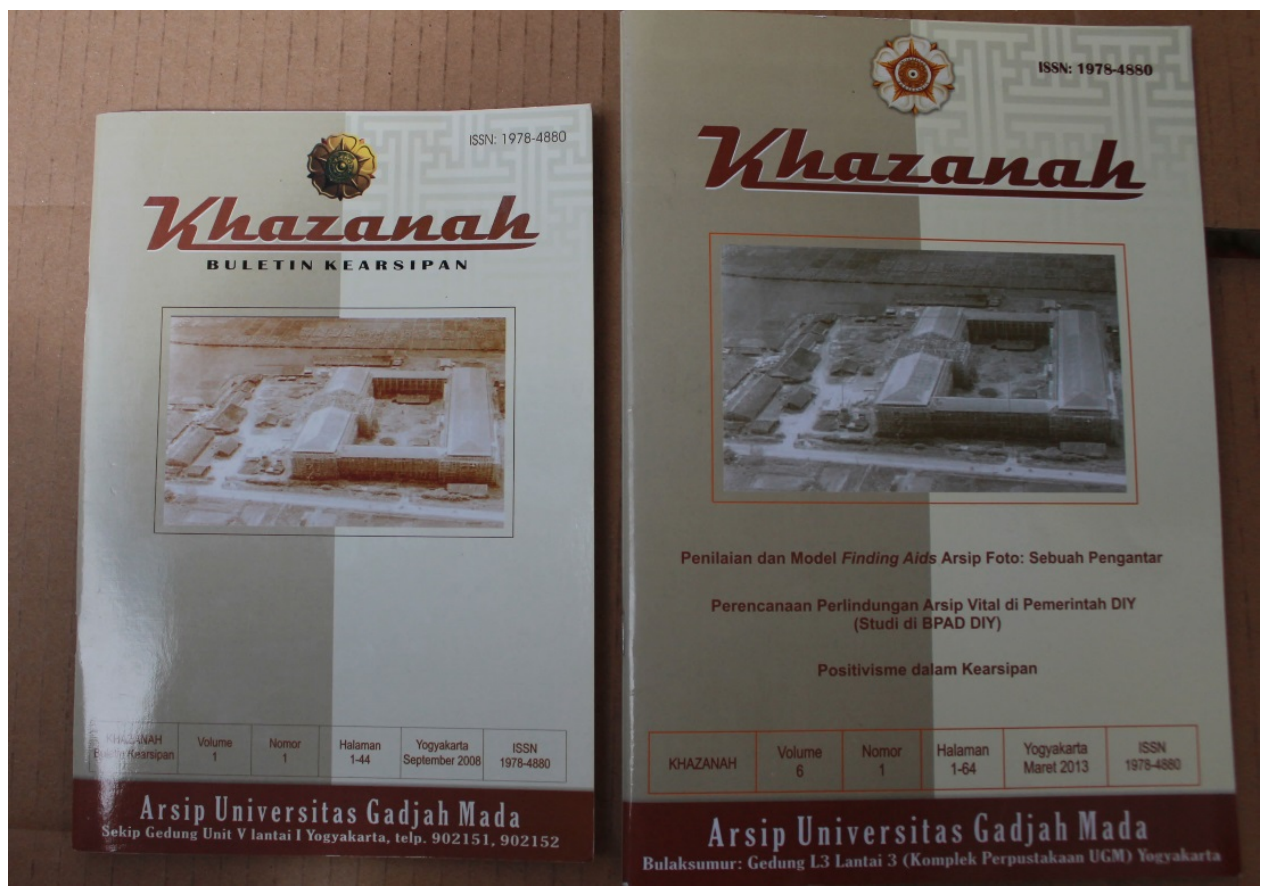

Gambar 3. Buletin Vol. 1 September 2008 dan Foto Buletin Vol. 6 No 1 Maret 2013

Khazanah memuat beberapa artikel dalam 3 kolom/rubrik. Pada edisi pertama September 2008 berisi dua kolom yaitu Opini dan Resensi. Opini berisi artikel hasil kajian dan penelitian kearsipan sedangkan Kolom Resensi berisi review atau resensi buku kearsipan. Volume 4 Nomor 1 Maret 2011, Khazanah menambah 1 kolom lagi yaitu
Telisik yang berisi artikel hasil penelitian tema tertentu yang bersumber pada khazanah arsip statis yang tersimpan di Arsip UGM. Jumlah artikel pada kolom Telisik pada volume 4 nomor 3 November 2011 ditambah menjadi 2 artikel. Tahun 2014 sejak terbitan nomor pertama jumlah artikel pada Kolom Telisik dikurangi menjadi 1. 


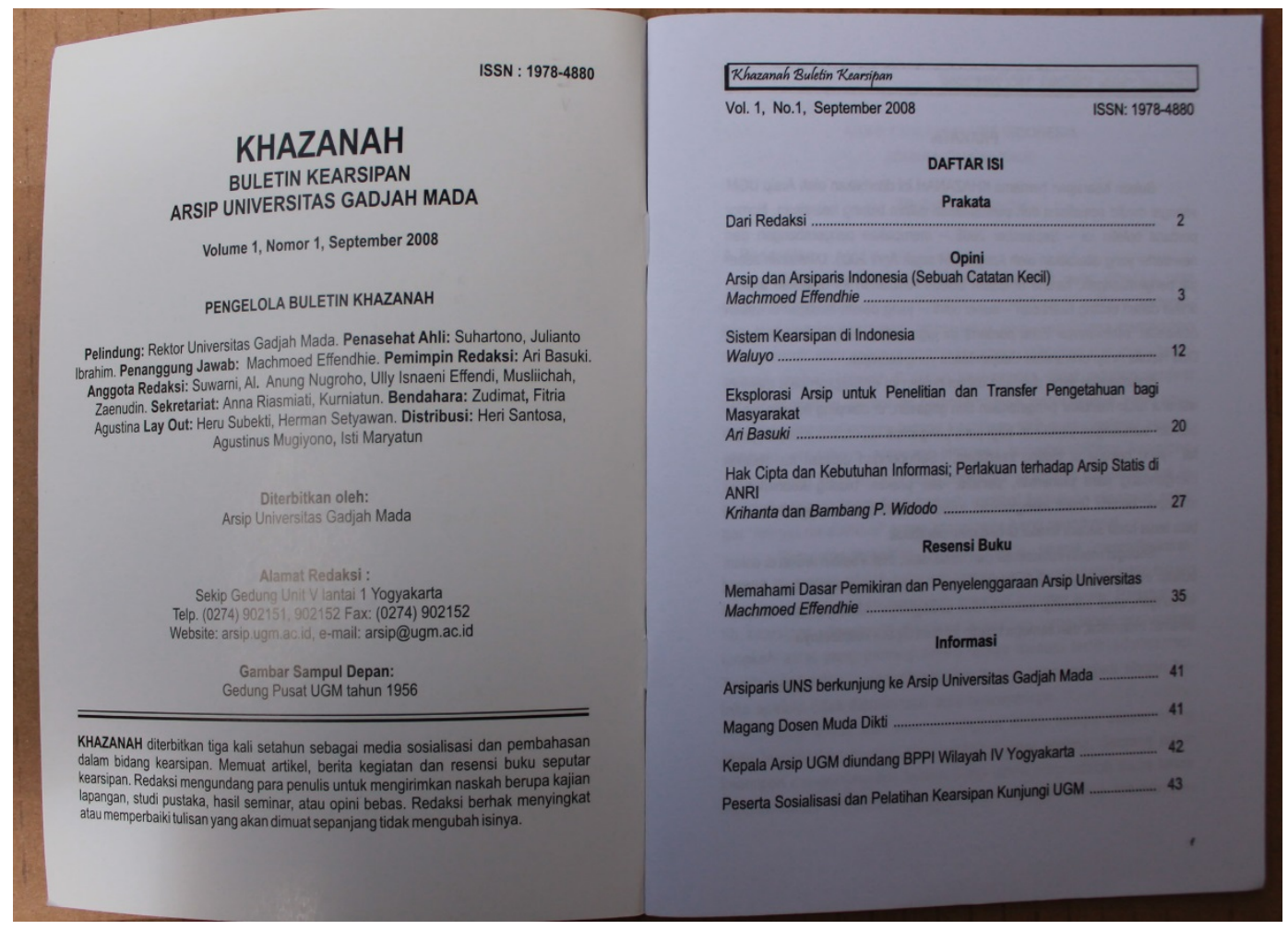

Gambar 4. Daftar Isi Khazanah Vol. 1 September 2008

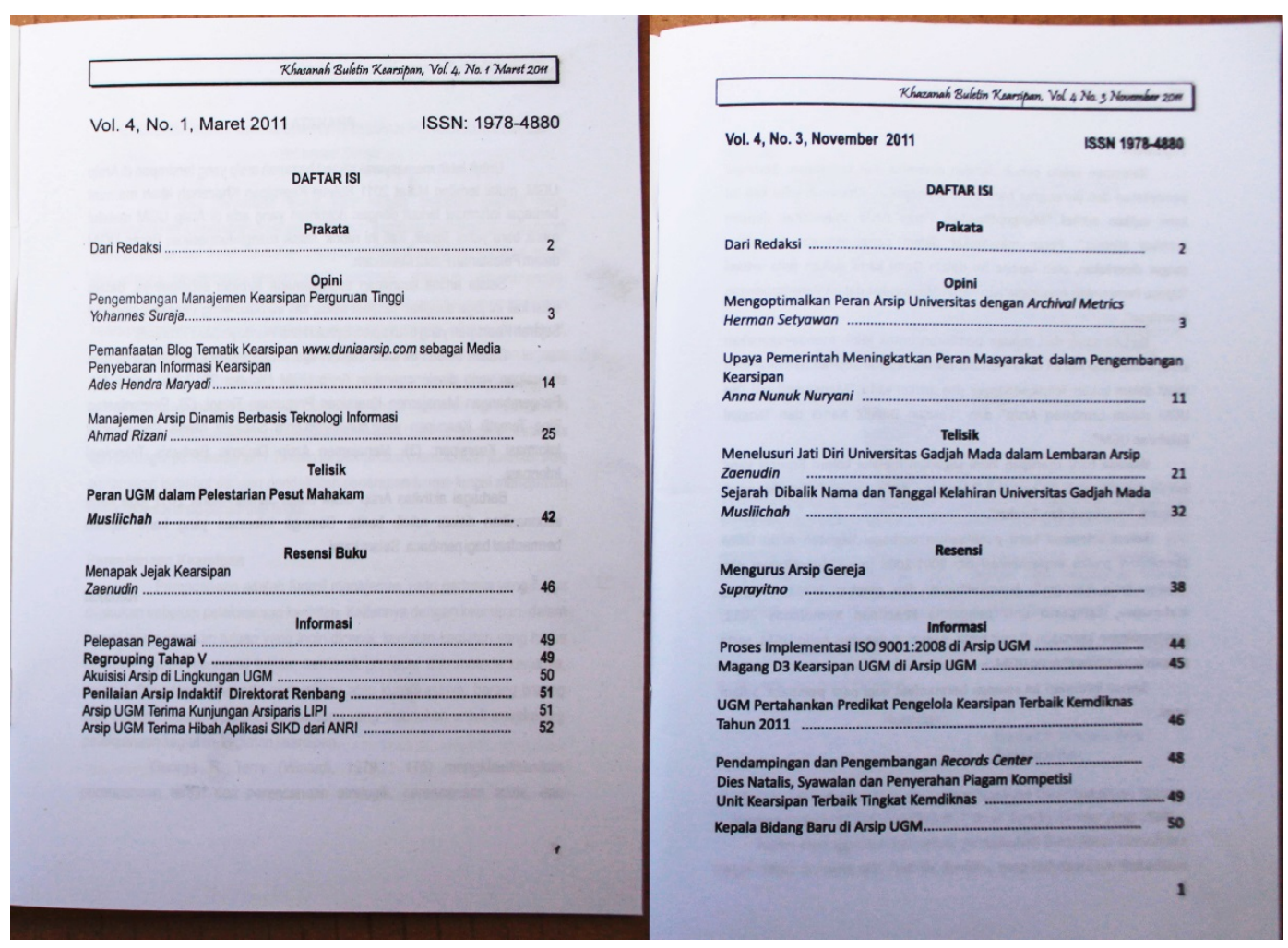

Gambar 5. Daftar Isi Khazanah Vol. 4 Nomor 1 Maret dan Nomor 3 November 2011 
Tahun 2017, Arsip UGM memutuskan untuk menerbitkan Khazanah sesuai dengan perijinan pertamanya yaitu sebagai jurnal. Nama yang digunakan untuk terbitan ini sesuai dengan nama yang diajukan dan disetujui pertama kali oleh PDII LIPI yaitu Khazanah: Jurnal Pengembangan Kearsipan. Khazanah: Jurnal Pengembangan Kearsipan ini diterbitkan dalam dua versi yaitu online dan cetak. Sejak 2017 juga dilakukan perubahan jumlah berkala terbitan. Khazanah: Jurnal Pengembangan Kearsipan diterbitkan 2 kali dalam setahun yaitu Mei dan November. Khazanah menyajikan 5 artikel dalam 3 kolom yaitu 3 artikel pada Kolom Opini, 1 artikel pada Kolom Telisik, dan 1 artikel pada Kolom Resensi.

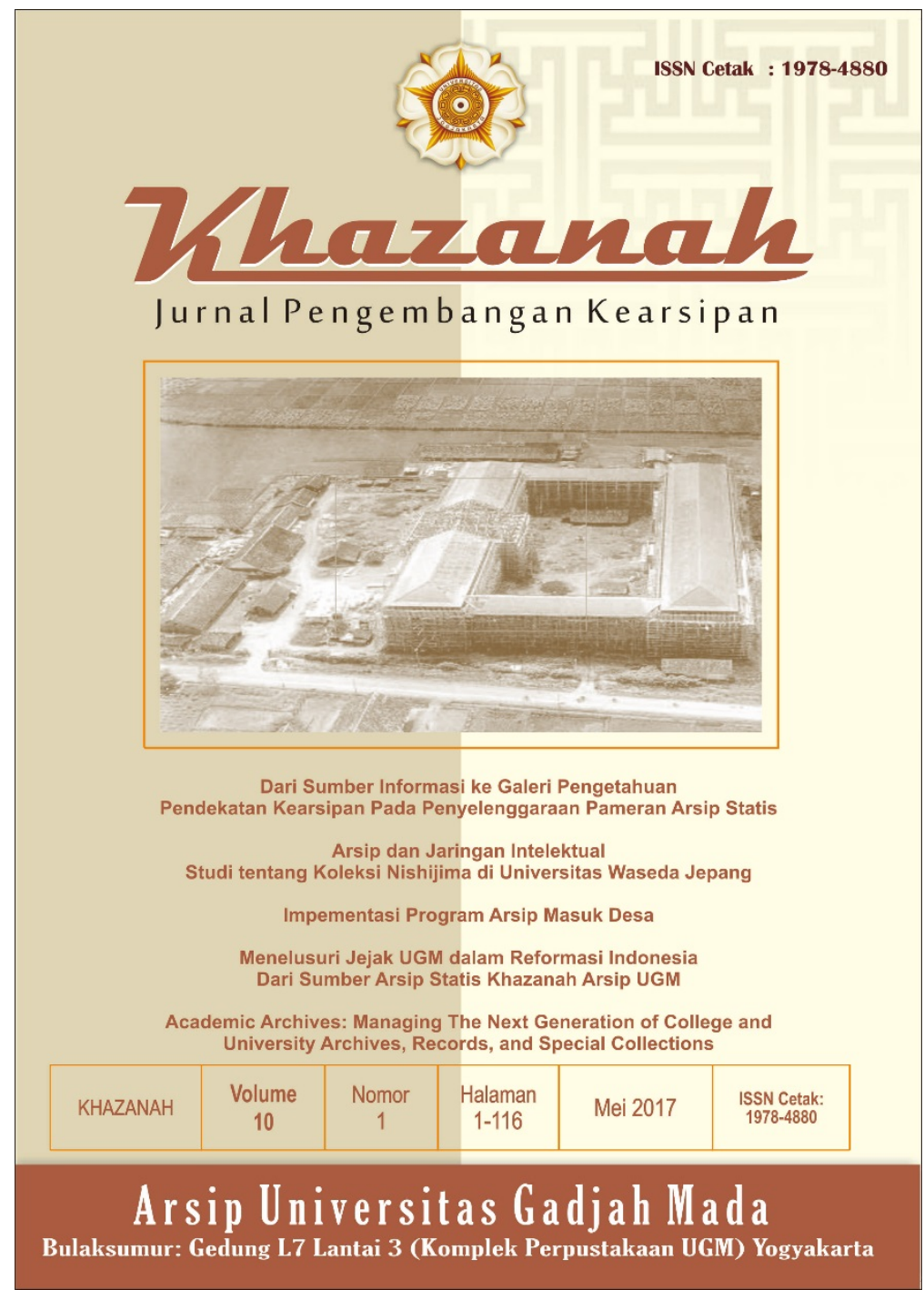

Gambar 6. Cover Khazanah Vol. 10 Nomor 1 Mei 2017 
Khazanah selama ini didistribusikan ke internal dan eksternal UGM. Internal UGM meliputi pimpinan unit kerja, perpustakaan dan arsiparis di lingkungan UGM. Eksternal UGM meliputi lembaga kearsipan nasional, lembaga kearsipan tingkat propinsi, lembaga kearsipan tingkat kabupaten/kota, perguruan tinggi negeri dan swasta tidak hanya di pulau jawa, kementerian, dan lembaga-lembaga lain baik BUMN maupun swasta yang menjadi relasi Arsip UGM. Penyebaran Khazanah cetak menggunakan jasa pos untuk eksternal UGM, sedangkan internal UGM dikirimkan oleh petugas ekspedisi dan jasa pengiriman Gama Logistik UGM. Meskipun Khazanah belum diterbitkan secara online akan tetapi format PDF Khazanah sudah diupload di laman Arsip UGM www.arsip.ugm.ac.id sejak tahun 2011 sehingga dapat diakses secara online oleh masyarakat luas.

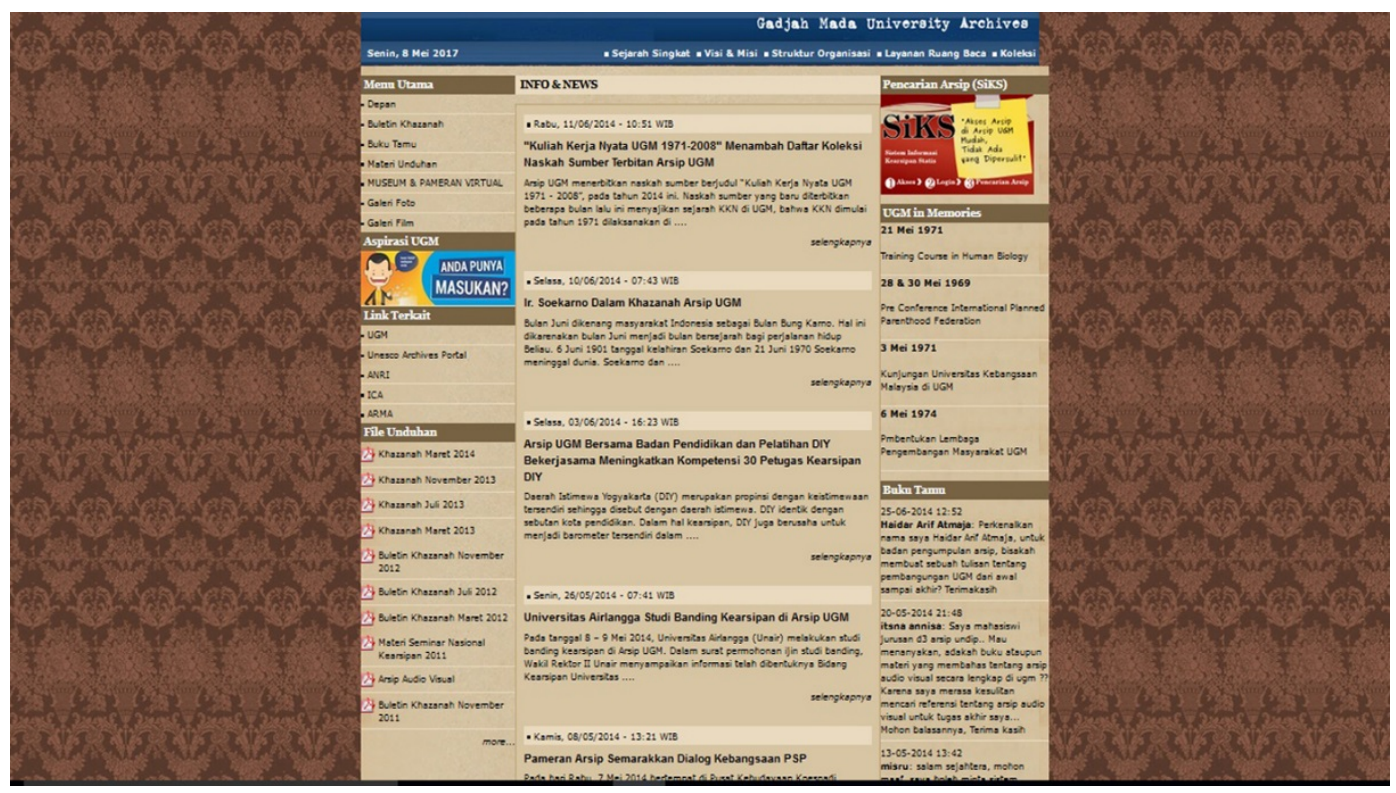

Gambar 7. Khazanah di Laman lama Arsip UGM

Khazanah: Jurnal Pengembangan Kearsipan diterbitkan untuk membantu mengembangkan dan menyebarluaskan gagasan-gagasan dan hasil-hasil kajian maupun penelitian di bidang kearsipan dalam rangka mengembangkan ilmu kearsipan di Indonesia.
Artikel-artikel yang disajikan dalam Khazanah diharapkan dapat menjadi sarana belajar dan berbagi informasi dan pengalaman di bidang kearsipan. 